\title{
LA BABILONIA QUE CONOCIERON LOS MAGOS EN FIGURAS DE BETHLEM DE GABRIEL MIRÓ
}

\author{
THE BABYLON THAT THE WISE MEN KNEW \\ IN FIGURAS DE BETHLEM BY GABRIEL MIRÓ
}

Laura Palomo Alepuz

Universidad de Alicante

laura.palomo.alepuz@gmail.com

Resumen: En el siguiente artículo se analiza la evolución genética que sufre el capítulo "III. Riegos. Borsipa. Babilonia", inserto en el bloque "Magos" de una obra inédita, fragmentaria y casi desconocida de Gabriel Miró: Figuras de Bethlem. Para ello, estudiamos las tres disposiciones manuscritas que se conservan de este apartado, teniendo en cuenta su organización textual, el uso de las fuentes empleadas para configurarlo y su contenido.

Palabras clave: Gabriel Miró; Figuras de Bethlem; obra inédita; fuentes; genética textual.

Aвstract: In the present paper we will analyse the genetic evolution "III. Riegos. Borsipa. Babilonia", wich is to be found inserted in the segment "Magos" of an unpublished, fragmentary and almost unknown work by Gabriel Miró: Figuras de Bethlem. To this end, we study the three existing drafts of this section, taking into consideration the textual organisation, the use of the sources employed in configurating the section and the content of the same.

Keywords: Gabriel Miró; Figuras de Bethlem; unpublished work; sources; textual genetics.

Recepción: 10 de septiembre de 2018; aceptación: 25 de marzo de 2019.

D.R. ( ) 2020. Nueva Revista de Filología Hispánica

Licencia Creative Commons Attribution-NonCommercial (CC BY-NC) 4.0 International 


\section{INTRODUCGIÓN}

Figuras de Bethlem es una obra incompleta e inédita de Gabriel Miró. Pertenece a un conjunto de libros de asunto bíblico que el autor planeaba incluir en la colección "Estampas Viejas"1, pero de la que únicamente vieron la luz los dos tomos de Figuras de la Pasión ${ }^{2}$ y un grupo de fragmentos de Figuras de Bethlem que el escritor publicó en forma de artículos en la prensa periódica.

Aunque Miró no pudo terminar su proyecto, tanto en su epistolario como en las entrevistas que concedió a lo largo de su vida, insistió frecuentemente en la importancia de esta serie bíblica que, según explica en la nota autobiográfica que publicó el Diario de Alicante en 1927, había imaginado desde su niñez $z^{3}$ y en la que trabajó a lo largo de muchos años incansablemente.

Las publicaciones de Figuras de Bethlem fueron apareciendo en la prensa periódica a partir de diciembre de 1919. La primera, "Bethleem", dividida en dos partes denominadas "Sendas y contornos" y "El camino alto", se publicó el 15 de diciembre de 1919 en la revista católica Voluntad. La siguiente, "El mesón de las caravanas. Camellos y luna", el 24 del mismo mes en La Publicidad de Barcelona. Poco después, los días 5, 6 y 7 de enero de 1920, salen en la edición de la noche de este mismo diario los artículos "Los Magos caminantes, I. La estrella y la cumbre", "Los Magos caminantes, II. La estrella y el camino" y "Los Magos caminantes, III. La estrella y los hombres", y un mes más tarde, en la revista Voluntad, aparece "Bethleem", dividido en "Los huertos", "Noemí” y "Ruth y Noemí”.

${ }^{1}$ Según la propia declaración del autor en carta a sus tías, empezó a concebir la colección en 1916 (Miró 2009, p. 229). A pesar de que comenzó a mencionar la gestación de la colección en 1918 en su epistolario, a su muerte, sobrevenida en 1930, todavía estaba incompleta. La nómina de las obras que la hubieran compuesto varió a lo largo de los años: en la primera versión, que aparecía al final del primer tomo de Figuras de la Pasión (1916), contenía seis libros (Figuras de la Pasión del Señor Iy II; Figuras de Bethleem [sic]; Figuras de discípulos; Santos y fiestas; Patriarcas y profetas y Monjes); en la segunda, que se encuentra en una nota autobiográfica que publicó el Diario de Alicante el 26 de marzo de 1927, menciona ocho (Monjes desaparece, y en su lugar figura un volumen denominado Calendario; los dos tomos de Figuras de la Pasión se integran en uno solo; y Patriarcas y reyes y Santos y fiestas se dividen en dos libros cada uno), y en la última variante, la lista de las Obras completas para la editorial Biblioteca Nueva, se recogen solamente seis (desaparecen los tomos Fiestas y Calendario).

${ }^{2}$ Miró publicó los dos tomos de Figuras de la Pasión del Señor en la editorial Doménech; el primero salió en 1916, y el segundo, en 1917.

${ }^{3}$ La publicación, a la que hemos aludido antes, iba firmada por José Castellón y llevaba por título "Novelistas de España. Entrevista con Gabriel Miró". Apareció por primera vez en el Diario de Alicante el 26 de marzo de 1927. Después, con el título de "Autobiografía”, figuró en el número del 1 de junio de 1931 de La Gaceta Literaria, dedicado a Miró con motivo del aniversario de su muerte. Luego, los editores de las Obras completas. Edición conmemorativa (1932-1949) incluyeron una transcripción del manuscrito de esta entrevista en el volumen 1. 
Luego de tres años, el 7 de enero de 1923, publica en La Nación de Buenos Aires el trabajo que lleva el título general de "Figuras de Bethlem", dividido en los apartados "Ruth", "El desierto y Etham", "Bethlem", "Ruth y Booz" y "David y Salomón". El mismo año, y en este diario, ve la luz el 23 de diciembre "Figuras de Bethlem: Caravanas", al mismo tiempo que en Los Lunes de "El Imparcial" de Madrid aparece "Los Magos caminantes".

Alrededor de dos años después, los días 9 y 10 de enero de 1925, salen en $\mathrm{El}$ Sol de Madrid dos artículos con el mismo nombre unitario: "Figuras de Bethlem"; el del día 9 contiene los subapartados "Ruth", "El desierto y Etham" y "Bethlem"; el del 10, "Ruth y Booz" y "David y Salomón". Al final del año, el 24 de diciembre, se publica en El Sol de Madrid "Figuras de Bethlem. Llegan san José y santa María".

Por último, los editores de las Obras completas. Edición conmemorativ $a^{4}$, recogen en el Apéndice al tomo 6, además de las versiones más avanzadas de entre los artículos que vieron la luz en la prensa periódica con sus correspondientes notas e índices de variantes, unas páginas que llevan el título de "Los tres caminantes", las cuales habrían sido entregadas por Miró, poco antes de morir, al representante de la revista argentina Caras y Caretas para su publicación, y que finalmente aparecieron el 12 de marzo de 1932 en el número 1745, según apunta Pedro Caravia Hevia en las notas suplementarias al tomo 6. Esta misma edición de las Obras completas de Miró fue la primera que recogió en el Apéndice al tomo 6 las versiones más avanzadas de los artículos aparecidos en la prensa periódica.

Por este motivo, hasta hace muy poco, lo que se conocía sobre Figuras de Bethlem eran los textos que se incluían en esta obra o en las posteriores que han tomado ésta como referencia ${ }^{5}$. Sin embargo, cuando en 2008 nos acercamos por primera vez al legado Gabriel Miró, conservado en la biblioteca alicantina que lleva su nombre, descubrimos que éste albergaba un conjunto de documentos manuscritos amplio y heterogéneo -tanto por sus fases de redacción (prerredaccional, redaccional y editorial) como por su tipología (carpetas, sobres, borradores, anotaciones, esquemas de contenido, índices, mapas y recortes de prensa) - que nos aportaban información adicional no sólo sobre la estructura, la gestación y el asunto de esta obra, sino también sobre su propia manera de crear (en general, Miró solía destruir los manuscritos de las obras que iba publicando).

${ }^{4}$ Esta edición, que consta de doce tomos, se publicó entre los años 1932 y 1949 en la editorial Altés de Barcelona por iniciativa de un grupo de amigos del escritor.

${ }^{5}$ Más tarde, los textos se han vuelto a incluir en la edición de las Obras completas de Biblioteca Nueva (1943), en las Obras escogidas de Aguilar (1950) y las Obras completas de la Biblioteca Castro-Fundación José de Castro (2006-2008), e incluso fueron editados en volumen independiente en 1961 con el título de Figuras de Bethlem. La conciencia mesiánica en Jesús en la colección de Obras completas publicadas por la Editorial Losada. 
Una vez determinados a hacer de este material nuestro objeto de estudio y a acometer nuestro análisis adoptando el enfoque metodológico de la genética textual ${ }^{6}$, resolvimos que centraríamos nuestro trabajo en la composición de Figuras de Bethlem partiendo de la transcripción de sus manuscritos y su propuesta de ordenación y el rastreo de sus fuentes.

El análisis del dosier de génesis ${ }^{7}$ de Figuras de Bethlem apunta a una estructura formada por tres grandes bloques de contenido, que a su vez están organizados en capítulos: una primera parte, denominada "Bethlem", en la que el autor delinea la historia bíblica de la célebre aldea; una segunda, llamada "Magos", en la que se recrea el viaje que realizaron los tres sacerdotes desde Persia hasta Belén; y una tercera, "Herodes", dedicada al rey Herodes el Grande 8

${ }^{6}$ Utilizamos en nuestro trabajo los términos de genética textual y crítica genética indistintamente, como hace HAY (2002). Sin embargo, algunos investigadores establecen una diferenciación entre ambos. El lector interesado puede encontrar una explicación sobre su distinción en el artículo de Emilio Pastor Platero, "La crítica genética: avatares y posibilidades de una disciplina", incluido en su compilación de textos significativos sobre esta disciplina, Genética textual (2008), o en el manual de Pierre-Marc Biasi, Génétique des textes (2011). Esta metodología surge en Francia de la mano de Hay en los años sesenta y se propone, en palabras del mismo BIASI, "renouveler la connaissance des textes à la lumière de leurs manuscrits en déplaçant l'interrogation critique de l'auteur vers l'écrivain, de l'écrit vers l'écriture, de la structure vers les processus, de l'œuvre vers sa genèse" (p. 11). La elección de este enfoque viene condicionada por la naturaleza de esta obra: inédita, fragmentaria y manuscrita.

${ }^{7}$ Empleamos este concepto teniendo en cuenta las definiciones de Almuth GRÉSILLON (1984, p. 109): "un ensemble constitué par les documents écrits que l'on peut attribuer dans l'après-coup à un projet d'écriture déterminé dont il importe peu qu'il ait abouti ou non à un texte publié", y Pierre Marc Biasi (2011, p. 67): "l'ensemble matériel des documents et manuscrits se rapportant à l'écriture de l'œuvre que l'on entend étudier".

8 Tanto la disposición del material manuscrito conservado (se encontraba organizado en una carpeta denominada "Bethlem", otra titulada "Herodes", una tercera en la que se había escrito "Obra incompleta" y un sobre grande que llevaba por nombre "Magos") como la última variante de índice, que encontramos en la curiosa anotación "Bethlem" (en la que se distinguen tres bloques correspondientes a los conceptos "Bethlem", "Magos" y "Herodes") apuntan en esta dirección. Además, la declaración en el artículo mencionado de 1927 de que toda la obra estaría "dentro de la órbita de Herodes" apoya esta hipótesis, ya que en la anotación anterior se establece una vinculación entre los tres apartados: el primero se desarrolla en la tierra elegida para el pueblo judío; el segundo, que trata el viaje de los Magos, se entiende como un proyecto humanitario y altruista, y el tercero, como una negación de los dos anteriores, la tierra y el humanismo, en la figura de un soberano egoísta y autoritario. Para obtener más información relativa a la configuración de Figuras de Bethlem, se puede consultar Palomo Alepuz 2018. 
Si nos centramos en el análisis del proceso de gestación del tercer capítulo de "Magos", denominado "III. Riegos. Borsipa. Babilonia”, a partir del examen de los manuscritos, veremos que toda esa parte ha sido concebida partiendo del fragmento del evangelio de san Mateo (II, 1-12) en el que se refiere la llegada de unos magos orientales a Jerusalén. En la ciudad, estos sabios preguntan por el rey de los judíos que acaba de nacer, lo que hace a Herodes sobresaltarse y reunir a todos sus doctores para que busquen en las escrituras la información pertinente a este suceso. Una vez localizada la cita de Micheas en la que se declara a Belén como la patria del caudillo de Israel, Herodes llama aparte a los Magos y los envía a la población, pidiéndoles que cuando encuentren al niño se lo comuniquen. Los Magos vuelven a avistar la estrella que habían seguido desde Persia brillando en el cielo y la siguen hasta que se detiene encima del lugar en el que estaba el recién nacido. Allí lo adoran y le ofrecen sus presentes. Poco después, habiéndoseles advertido en sueños que no volvieran a la corte de Herodes, se retiran a su país por otro camino.

Tanto en el texto bíblico como en las reelaboraciones culturales posteriores, el relato suele centrarse en el momento de la adoración al niño. Sin embargo, Miró hace una recreación del viaje que los sacerdotes llevan a cabo a través de las tierras de Persia, Babilonia, Asiria, Siria, Líbano y Palestina mediante la cual demuestra sus conocimientos sobre historia, arqueología, historia del arte y erudición bíblica, al tiempo que evidencia sus dotes como novelista. El resultado es un texto de gran belleza evocativa plagado de referencias culturales.

En efecto, el autor se sirve de algunos de los libros que tenía en su biblioteca personal, que, como señala Giménez Caballero en un artículo publicado en El Sol el 20 de abril de 1928, parecía más la de un sabio oriental que la de un poeta. Entre estas fuentes, dos tienen un papel preponderante en la configuración de este capítulo: Heródoto ${ }^{9}$ y el Dictionnaire de la Bible, coordinado por Fulcran Vigouroux $^{10}$.

${ }^{9}$ El lector interesado en ahondar en el aspecto de la influencia de Heródoto en Figuras de Bethlem puede ver Palomo Alepuz 2012.

${ }_{10}$ A diferencia del influjo de Heródoto, que se condensa especialmente en esta parte, el Dictionnaire de la Bible es una referencia fundamental para toda la obra. De hecho, parece ser la razón de que Miró modificase el esquema estructural original de la obra, más ingenuo y sencillo, como el que incluye en una carta que envía a su amigo Ricardo Baeza en 1919, en que los capítulos parecen remitir a las figuras tradicionales del belén, para convertir su libro en el tríptico voluminoso y erudito que, según todos los indicios, habría sido Figuras de Bethlem. Véase, para más información sobre el tratamiento de las fuentes en esta obra, Palomo Alepuz 2017. 
Heródoto es uno de los autores de la Antigüedad predilectos de Miró. De hecho, en el artículo "El turismo y la perdiz", recogido en Glosas de Sigüenza (1952), indica que no existen ojos que se hayan complacido tanto en mirar como los del historiador de Halicarnaso. Por varias razones, el escritor gustaba de insertar referencias a los clásicos -de quienes era lector apasionado-, especialmente en su obra histórica: en primer lugar, porque era una forma de manifestar su admiración y el placer que su acercamiento le habían deparado; en segundo, porque las obras griegas y romanas históricas de la Antigüedad, por su condición de textos literarios, se avenían a su proyecto novelístico; en tercero, porque de esta manera dotaban su texto de verosimilitud.

Además, en el caso de Heródoto, podrían sumarse otras dos causas: por un lado, el historiador fue un viajero incansable, visitó los territorios sobre los que escribe, conoció a sus habitantes y recogió relatos in situ, lo que proporcionaba a su narración frescura, naturalidad y una dimensión experiencial; por otro, es un gran contador de historias, por lo que Miró recurriría a él para enriquecer su narración.

Sin embargo, Miró siempre matiza la información que extrae de Heródoto con la que aparecía en otros manuales históricos contemporáneos. En este sentido, es especialmente importante el mencionado Dictionnaire de la Bible, coordinado por Fulcran Vigouroux, cuya entrada sobre la torre de Babel es esencial en la configuración de este capítulo, como veremos más adelante.

De este modo, con los datos que Miró extrae de la lectura de estas fuentes imagina un itinerario ${ }^{11}$ para el cual diseña sus propios mapas $^{12}$, recrea maravillas del mundo antiguo como los jardines colgantes babilonios, retrata monumentos como las torres sagradas o zigurats, cuyos restos arqueológicos describían los historiadores a los que el escritor leía con fruición, e intercala historias que, por su sabor, por la reflexión que inevitablemente propician sobre lo mejor y lo peor del género humano, le atraen y quiere recuperar.

Además, Gabriel Miró seguía con gran atención los nuevos descubrimientos arqueológicos que se hacían en todo el Oriente próximo. En concreto, la historia de Babilonia le maravillaba quizá por su grandeza o su decadencia, el nivel de desarrollo al que llegó su pueblo, sus momentos de horror y de esplendor o su arte. Asimismo, posiblemente esta fascinación de Miró por una cultura lejana, exótica y remota como la Babilonia tiene que ver con una cuestión de época,

${ }^{11}$ Los únicos datos respecto al viaje de los Magos que el autor encontró en la entrada dedicada a estos personajes son que podrían haber salido de Persépolis y que, con toda probabilidad, atravesarían los valles del Éufrates y del Jordán.

${ }^{12}$ En el dosier de génesis de Figuras de Bethlem encontramos diversos mapas que había dibujado el propio autor en los que traza la ruta que pudieron haber seguido los Magos. 
un vestigio de su período de formación juvenil en la etapa de mayor auge del Modernismo. El hecho es que en el texto del capítulo "Riegos. Borsipa. Babilonia", la narración transmite un interés especial por esta civilización.

Por lo demás, a pesar de que Figuras de Bethlem es una obra incompleta y fragmentaria, de las tres partes principales que la forman, "Magos" es la que se encuentra en un estado más avanzado de gestación y de la que más textualizaciones pertenecientes a fases de redacción distintas conservamos.

En el caso de "III. Riegos. Borsipa. Babilonia" contamos con material correspondiente a tres etapas de creación que tienen su reflejo en tres disposiciones del material: la primera, bastante breve, formada por tres capítulos: "La estrella y la cumbre", "La estrella y el camino" y "La estrella y los hombres"; la segunda, más larga, estructurada mediante dos tipos de símbolos (primero, " $\$$ " y, más tarde, tres "X" que forman un triángulo); y la tercera, organizada en una serie de sobres correlativos, designados por un título común (el del bloque) y otro específico (el del capítulo), lo que permite analizar su configuración y entender de una forma gráfica cómo trabajaba Miró y de qué manera, en particular, concibió este capítulo.

Las posibilidades para el estudio que ofrecen los materiales manuscritos de este capítulo, junto a su riqueza intertextual, su calidad literaria, su originalidad, su belleza y la admiración que el escritor testimoniaba por el territorio en el que transcurre la acción, también el relativismo ideológico que tiñe toda la obra y que en este fragmento se avista en determinadas reflexiones que señalaremos más adelante, nos llevaron a hacer del análisis de la gestación del capítulo de marras el objeto de estudio de este trabajo.

\section{La gestación del apartado "III. Riegos. Borsipa. Babilonia"}

En las versiones más avanzadas de la primera disposición -por ejemplo, la que plantean los artículos publicados en La Publicidad los días 5, 6 y 7 de enero de 1920- el paso por territorio babilonio se trata brevemente en el último apartado, "La estrella y los hombres". Los Magos llegan a la célebre metrópoli después de haber atravesado Uruk y la cordillera del Zagros:

...Han pasado la umbría, densa y verde, como una cuajada de limo, de los muros de Babilónia ${ }^{13}$, los muros de doscientos codos reales de altitud. Babilónia duerme tendida en el silencio y la hierba. Sus cien puertas de

13 Para los criterios de transcripción del texto en esta y las demás citas, véase el Anexo; para este caso en concreto, el punto número 6, referente a las faltas ortográficas. 
bronce se van rajando como las losas de los sepulcros. Pero aún rebrotan y florecen sus pensiles; las raíces cuelgan y se agarran en los escombros de los barrios inmensos de obradores, donde se acumuló el tragín y la sensibilidad de todas las razas de Asia. Jardines colgados entre pilares huecos que esconden los ingenios hidráulicos para subir del Eufrates el riego de los céspedes y de los árboles floridos. Las torres del templo de Bel, despojadas de las estátuas de oro de sus dioses, hunden en el azul sus quijadas de piedras rotas; y en las ruinas de la Ziggurat ${ }^{14}$ abren sus brazos descarnados los sacerdotes, y anidan sus aves agoreras que vuelan con silencio de alas de paño, y rasgan la quietud con su grito de herrumbre despertando los ladridos de todos los muladares.

Y tras ofrecer esta somera descripción del estado actual de la ciudad, la parte dedicada a la etapa de Babilonia finaliza.

Sin embargo, en la segunda fase de redacción, manuscrita y considerablemente más extensa que la anterior, este trayecto se modifica y se ensancha mediante la adición de sucesos, datos y referencias literarias.

En relación con los cambios, dos son destacables: el primero es que los Magos no atraviesan en su camino hacia Babilonia la ciudad de Uruk, como en las composiciones más antiguas, pero, y esto es muy interesante desde un punto de vista genético, Miró solamente elimina la referencia a esta ciudad, no el contenido que aparecía vinculado a ella, el cual aparece posteriormente referido a otro lugar de Mesopotamia, $\mathrm{Ur}^{15}$, insertado en una analepsis mediante la cual Gaspar recuerda su ciudad natal. Vemos primero la información relacionada con Uruk:

Sobre el cristal del cielo se deslizan las garzas en busca de las albercas dormidas de Uruk, la vieja ciudad pomposa, ahora claustro de matemáticos y teósofos, de ancianos que palidecen en la meditación ( $L a$ Publicidad, 6 de enero de 1920).

Y más tarde conectada con Ur:

La ciudad gloriosa ciudad va rompiendose cayendose rota $^{16}$ y todavía es residencia de matemáticos, de teósofos, $\mathbf{d e}^{17}$ ceramistas. En las afueras brotan rodales de árboledas de te los viejos bosques y en euyas sombras su frescura profunda ${ }^{18}$ se acogían los de Ur en las horas de sol, el sol

${ }^{14}$ Respetamos el criterio del autor que utiliza la palabra ziggurat en femenino, siguiendo las fuentes de consulta francesas que utilizaba con frecuencia.

${ }^{15}$ Seguramente, la información que incluye el autor sobre Ur la pudo tomar de La Bible et les découvertes en Palestine et Egypte et Assyrie del mismo Vigouroux (1879, t. 1, p. 351).

\footnotetext{
16 Tachado: a pedazos.

17 Tachado: $y$.

18 Tachado: donde.
} 
de la Mesopotamia que devora y raja $^{19}$ la planicie humeante (Cuart. 3r [1], "Bethlem. Figuras de Bethlem").

Y en cuanto al segundo, Miró retrasa el paso cerca del monte Zagros. Si en las primeras redacciones los Magos percibían la belleza de esta cordillera antes de visitar Babilonia, en la segunda lo hacen cuando salen de esta ciudad.

Como apuntábamos antes, el capítulo se amplifica considerablemente. La sucinta mención a los muros, puertas y jardines de la ciudad se convierte en una narración pormenorizada y salpicada de referencias literarias, la mayor parte de las cuales procede de Los nueve libros de la historia de Heródoto y del Dictionnaire de la Bible de Fulcran Vigouroux, como ya hemos dicho y analizaremos con mayor detalle a medida que vayan apareciendo.

La entrada al territorio babilonio se anuncia con el avistamiento de un oasis de palmeras que es descrito así en la redacción $\mathrm{I}^{20}$ :

Poco a poco, el palmeral ${ }^{21}$ oprime $^{22}$ la estepa ${ }^{23}$. El aire viene amargo de pólen. Las palmeras palmeras son más altas y generosas que las de Libia. Su fruta maravilló a los griegos llamándola el ambar dulce. Arbol pródigo; que se $\mathbf{s e}^{24}$ sustenta con poco terrón y acobijo. Ha compensado ${ }^{25}$ a la Mesopotamia de la ausencia de la higuera, del olivo y de la viña. Mana miel, aceite y el licor que conforta como el vino; la médula sacia como el pan; de los huesos molidos de los dátiles se hacen tortas para cebar los bueyes y se beneficia el herraj para los hornos; sus eortezasy fibras y cortezas dan sogas, grasas, tejidos y aparejos; y de los troncos salen ${ }^{26}$ dinteles, puertas y techumbres (Cuart. 12r [1] "Bethlem. Magos [I]").

Y a este fragmento, que el autor ha elaborado trenzando información proveniente de Heródoto (en Babilonia no crece el olivo sino la palmera, que proporciona a los habitantes de estas tierras miel, aceite

19 Tachado: desgarra.

20 Agrupamos los borradores en redacciones, teniendo en cuenta la similitud en relación con el tipo de papel, tinta y letra, cantidad de tachaduras, número de página y clase de numeración. Una vez organizadas, las datamos aproximadamente después de haber analizado los cambios que presentaban en forma de tachaduras, adiciones y sustituciones. Finalmente, las nombramos siguiendo las letras del alfabeto. En el caso de la segunda disposición del apartado "Magos", encontramos diez composiciones. Como ninguna de ellas está terminada, para analizar los cambios que Miró introduce en esta segunda disposición, nos guiaremos principalmente por el contenido de la $\mathrm{G}$, casi completa, y la I, que es una de las más avanzadas.

21 Tachado: se fue.

22 Modificado: oprimiendo.

23 Tachado: el confin de macizos de palmeral.

24 Tachado: todo impulso hacia el cielo y se.

25 Tachado: Compensa.

26 Tachado: se labran muebles. 
y vino) y de Jenofonte ${ }^{27}$ (la sorpresa provocada por el conocimiento de su fruto, su comparación con el ámbar y la costumbre de comer su médula), sucede otro, en el que la influencia del primer autor sigue siendo decisiva -es evidente incluso por el hecho de que Miró decida mencionar al historiador, porque en otras ocasiones lo sigue sin hacerlo explícito-, donde se relata cómo los Magos se adentran en el trazado geométrico de los canales que unos reyes lejanos idearon hace mucho tiempo para aprovechar el agua del Éufrates; se describe la diversidad de los cultivos que esta tierra fecunda produce; se comenta el asombro que causa a los Magos el desarrollo de un fenómeno pintoresco: el de los buhoneros armenios que transportan río arriba en sus acémilas las naves "deshinchadas" que les habían servido para bajar hasta el territorio babilonio sus mercancías:

Se cruzaba y rebultaba la planicie de escombros de canales, los canales abiertos por tros reyes fundadores de castas divinas que enhebraron los grandes ríos en la faz de ${ }^{28}$ toda la Mesopotamia colmándola de frutos y de pan. En algunas comarcas iban desenterrando las venas hidráulicas; y la inmensidad se trenzaba de $^{29}$ una geometria de de $^{30}$ riegos. Wolvía a Crecía la mies de hoja zumosa y carnal, y el maíz y el sésamo tan altos $^{31}$ como árboles según Herodoto ${ }^{32}$ y se agigantaban todas las especies agrícolas en el país de los colosos de la ladrillos. Crecían ${ }^{33}$ las sus aldeas, Eran de pilones de argamasa, de cubos de asfalto $^{34}$ a la sombra de los sauces y abedules en y los enormes cañares y junqueras, que han inspirado un motivo ornamental de los palacios ${ }^{35}$ y por el Eufrates ${ }^{36}$ pasaban las recuas en armadías de odres y olmo $^{37}$ y eargadas de reeuas que cuando dejaban su carga ${ }^{38}$ en los poblados volvían a remontar las orillas llevando los cueros des[hinchados] vacíos que les sirvieron para la navegación (Cuart. 9r [2], "Bethlem. Magos [I]").

Entre todos los textos que decide ampliar Miró en esta segunda versión del capítulo, uno de los que sin duda adquieren importancia

27 Miró conservaba en su biblioteca una edición de la Anábasis (1882) y otra de la Ciropedia (1882), que seguramente consultó para la elaboración de Figuras de Bethlem. Anábasis, concretamente, es fuente de la información utilizada para el fragmento citado.

28 Tachado: por.

29 Tachado: y los magos descansaban sus ojos en.

30 Tachado: cultivos $y$.

31 Tachado: grandes.

32 Tachado: que maravilló a Herodoto.

33 Tachado en la línea inferior: Volvian a brotar. Encima de ésta aparece también eliminado Recrecían.

34 Tachado: fango y de palmeras.

35 Tachado: cargadas de recuas que.

36 Tachado: los ríos.

37 Tachado: juncos.

38 Tachado: sus mercancías. 
capital, por su valor literario y su repercusión narrativa, es el dedicado al gran zigurat de Borsipa, plagado de referencias a Heródoto y, muy especialmente, al Dictionnaire de la Bible.

La visión del templo, cuyos relieves los Magos advierten mucho antes de llegar a la ciudad sagrada ${ }^{39}$, desencadena un intercambio de comentarios entre los miembros de la caravana junto a la cual los sacerdotes hacen esta parte del trayecto. A las primeras exclamaciones de asombro ("iLa gran ${ }^{40}$ ziggurat de Borssipa ${ }^{41}$ !", "El Templo de Bors" sipa de las siete esferas, te los cinco planetas y delsol y la luna!") sucede la emocionada intervención del más anciano de los camelleros:

-Ved la unica ${ }^{42}$ obra de los hombres que estuvosumergida en las aguas yen eleieno ${ }^{43}$ y todavía resiste los siglos. Yo la he tocado seis veces, y ahora ${ }^{44}$ podré de nuevo, sentirla en mi piel y besarla. Su base tiene cuarenta y dos medidas agrarias, está consagrada a Saturno, y como Saturno gira más allá de toda luz por eso esa primera franja la untaron de negro con los betunes de los pozos de Hit y de Samarah ${ }^{45} ¥ \mathbf{E} \mathbf{~}^{46}$ segundo piso es el de Jupiter, y tiene los ladrillos $\mathbf{d e}^{47}$ color de naranja; y el tercero, de Marte, es de la arcilla más roja que sale más roja de $\mathbf{l a}^{48}$ hornada $^{49}$; el cuarto, que representa el sol, es de chapas/ láminas ${ }^{50}$ doradas; el quinto, dedicado a Venus, de amarillo muy dulce; el sexto, de un azul vidriado porque pertenece a Mercurio; y el último, a la luna, de plata, se desvanece en la claridad del aire (Cuart. 10r [1], "Bethlem. Magos [I]").

Y la información que éste proporciona es completada en seguida con la que ofrece un mayoral, quien explica que hay una rampa que envuelve toda la construcción, enroscándose como una serpiente, situada en el lugar más sombrío y fresco para que la subida sea menos fatigosa. También comenta que en la parte más alta hay una escultura del dios, realizada en oro, y que en los primeros pisos están cavadas las cámaras de los sacerdotes donde se acumulaban sabiduría y riquezas ${ }^{51}$.

${ }^{39}$ Es posible que Miró se inspirase en el relato del viajero M. Rich, que visitó las ruinas del zigurat, incluido en Vigouroux 1879, t. 1, pp. 293-294.

${ }^{40}$ Tachado: gran.

${ }^{41}$ Tachado: sagrada.

42 Tachado: una.

43 Tachado: del diluvio.

${ }_{44}$ Tachado: dentro de poco.

45 Tachado: de Babilonia.

${ }^{46}$ Modificado: $e l$.

47 Tachado: $e l$.

48 Tachado: del.

${ }^{49}$ Modificado: horno.

${ }_{50}$ Aparecen las dos opciones.

${ }^{51}$ Algunos de estos datos los encuentra Miró en la edición de 1898 (t. 1, pp. 119-120) de Los nueve libros de la Historia de Heródoto que conservaba en su biblioteca personal. 
A continuación, interviene el patriarca de una tribu judía, el cual identifica el zigurat de Borsipa como la torre de Babel de la que habla el Génesis:

-Cúlpense los hombres como sean culpados los que alzaban esa torre para Hegar tocar el cielo. Aquí se juntaron y dijeron: Amasaremos ladrillos y los coceremos a la lumbre y levantaremos una torre que llegue hasta Dios, y nuestro nombre quedará siempre en la memoria (Cuart. 10r [1], "Bethlem. Magos [I]").

Esta referencia a la escritura es contestada inmediatamente por Gaspar, quien explica que ellos tres provienen de una montaña en la cual han pasado muchos años recluidos en soledad y silencio con la intención de acercarse al cielo. Entonces, un pastor responde que en ese caso han cometido el mismo pecado que los antiguos hombres. Pero el patriarca redarguye tal afirmación:

-No así, porque desde la su cumbre obra ya de Dios, estos adoraban, y los otros remedaron una cumbre y quisieron remedar al Señor, y el Señor dijo: "-He aquí un solo pueblo y un solo lenguaje para todas las gentes. Iremos y los confundiremos.-" Y bajó y dispersó a los hombres sobre la haz de la tierra (Cuart. 10r, "Bethlem. Magos [I]").

La cita bíblica recuerda a los Magos una tradición que habían leído en los papiros de Abydena, sacerdote de Osiris: "Los hombres se vanagloriaron de su talla corpulenta y de sus fuerzas muy grandes y menospreciaron a la divinidad edificando una torre hasta los cielos, y vinieron los vendavales y derrumbaron la obra encima de sus constructores".

Seguidamente, una mujer hermosa pregunta sonriendo por qué la divinidad fue propicia a la labor de reconstrucción de esta torre llevada a cabo por Nabucodonosor y, sin embargo, castigó a los hombres primitivos, a lo que el patriarca contesta que la causa del favor de Dios se debe a que el rey babilonio no quería construir una escalera contra el cielo, sino un altar a la divinidad ${ }^{52}$.

Por último, este fragmento se cierra con la perplejidad de los Magos que confiesan que, a pesar de su sabiduría, no son capaces de entender las distintas verdades disputadas por las gentes, como si la vieja edificación todavía pudiese proyectar la oscuridad de la interpretación de la palabra, lo que es síntoma, desde nuestra perspectiva, de un relativismo ideológico que, si bien es patente en toda la obra,

52 Miró identifica la torre de Babel con el zigurat de Babilonia, con la torre que aparece en la escritura sobre los sacerdotes de Osiris y con el rey Nabucodonosor, con toda seguridad, por influencia de VIGOURoux. El análisis parece sugerir que siguió de cerca el texto de la entrada del Dictionnaire (1912-1922) dedicada a la torre de Babel. 
alcanza su punto culminante en la narración de "Magos" al producirse, a lo largo del relato, el choque constante entre su idealismo y la realidad. Los sacerdotes, en su pureza y su inexperiencia, esperan que los grupos sociales con los que van coincidiendo en su camino acojan con la misma ilusión que los mueve a ellos la noticia del advenimiento de un nuevo rey que salvará a la humanidad; sin embargo, se encuentran con el recelo de las gentes al mismo tiempo que constatan que la misma complejidad y limitación del ser humano hace irrealizable cualquier ideal.

Al pasaje sobre el zigurat le sucede otro en el que se describe la ciudad de Babilonia. Aunque en las primeras textualizaciones también se mencionaban algunos de sus rasgos más característicos, en ésta se pintan detalladamente. En primer lugar, la narración se centra en los rasgos arquitectónicos más sobresalientes de la ciudad: sus muros, sus puertas, sus jardines colgantes:

Pasaron la umbría verde como mojada de $\operatorname{limo}^{53}$ de los muros de Babilonia, los muros de doscientos codos reales y tan anchos que podían correr seis carros de frente. Babilonia duerme La ciudad tenía cien puertas de bronce. Aun retoñan algunos pensiles troncos de los colgados jardines ${ }^{54}$; salen $^{55}$ las raíces por ${ }^{56}$ las grietas de los techos de las terrazas tendidos entre ${ }^{57}$ pilares enormes esmaltados, y ta enorme y, en medio, caía ${ }^{58}$ podrida la enorme columna hueca que escondió los ingenios hidraulicos para subir el riego del Éufrates. el riego de los colgados jardines (Cuart. 11r [1], "Figuras de Bethlem. 10 cuartillas").

En segundo, el narrador dirige su mirada hacia sus calles y sus gentes:

Nunca, ni en la soledad de su roca ${ }^{59}$ habían tenido $\operatorname{los}^{60}$ emoción magos la emoción del silencio como en ${ }^{61}$ la inmensa ciudad. Ensualtar Ceñi$\operatorname{dos}^{62}$ por los horizontes y las órbitas de los astros ellos habían recordado la gloria de la ciudad de la $^{63}$ salían los ejércitos para traer cautivos a los pueblos más lejanos ${ }^{64}$. Babilonia torbellino de todas las razas, de

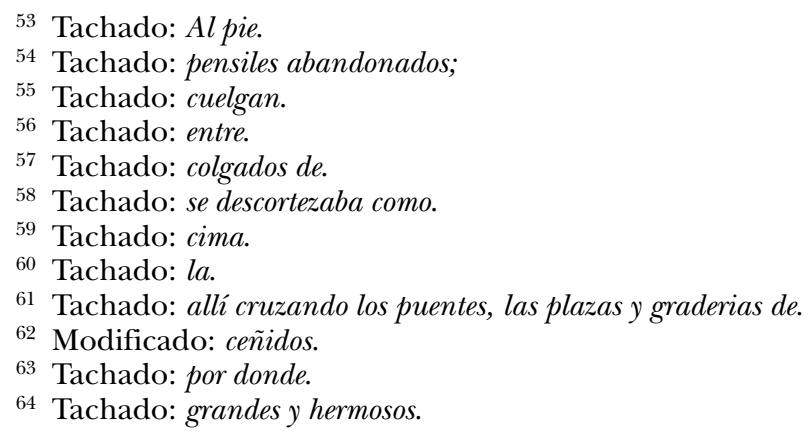


todos los trájines y delicias ${ }^{65}$ de Oriente. / / Sus calles, sus plazas, sus rampas y muelles deslumbraban con los olores de las caravanas que salían abastecían de riquezas el mundo ${ }^{66}$, magnificados por los cortejos reales y por las procesiones de los dioses te oro deslumbradores, y los humos de los perfumes cegaban el cielo (Cuartillas 11r [1] y 12v [1], "Figuras de Bethlem. 10 cuartillas").

En relación con sus gentes, se introduce la referencia a tres de sus costumbres, la información de las cuales ha tomado Miró con toda seguridad de Los nueve libros de la historia de Heródoto: la primera tiene que ver con el hábito que tenían los caldeos de sacar a sus enfermos al portal de sus casas para que los que pasaran por su calle les dieran consejos sobre la forma de curarse; la segunda es la descripción de los ropajes que llevaban sus ancianos, y la tercera, la costumbre que tenía un pueblo babilonio de comer ciertas tortas hechas a base de pescado machacado:

Véan En $^{67}$ algunos $^{68}$ portales mugrientos veían tendidos los enfermos esperando que los de las gentes que pasaban el consejo de su remedio lo mismo que en los tiempos antiguos.

Pasaban algunos ancianos todavia con sus vestiduras blancas ${ }^{69}$ según las llevaban los caldeos de los días felices ${ }^{70}$ : la túnica larga de lino, la corta de lana, y el capotillo hasta el codo; el ancho anillo y el bastón con el puño labrado en figura de lirio, de rosa, de fruta o de águila; y en sus ojos la mirada de la desgracia irremediable de muchos siglos.

(*) Por el arrabal de los tejedores de paños telares insignes se hundieron en otro que hedía de salmueras podridas y secaderos de peees de ríos, donde vivía un pueblo hórrido que se alimenta te masas de peces machacados de los que tespu[és] amasan tortas que cuecen en to[s] recoldos como panes (Cuartillas 12v [1], "Bethlem. Figuras de Bethlem. 10 cuartillas" y 13r [2], "Bethlem. Magos [I]").

A continuación, Gaspar y Baltasar recuerdan un episodio de la historia de Babilonia que también recogió Miró de la obra del historiador griego. Los babilonios, cercados por el ejército de Darío, decidieron degollar a todas las mujeres y consiguieron resistir un año. Uno de los sátrapas de Darío, Zopiro, viendo que el asedio se prolongaba, y queriendo socorrer a su rey, tomó la decisión de poner en

\footnotetext{
${ }^{65}$ Tachado: de sensualidades y trájines.

66 Tachado: del mundo.

${ }^{67}$ Modificado: en.

68 Tachado: los.

${ }^{69}$ Tachado: vestigi[ios].

70 Tachado: de épocas glori[osas].
} 
práctica un plan para rendir la ciudad: se cercenó la nariz y las orejas y se desolló la espalda; mutilado, se hizo pasar por un rebelde que había sido castigado y pidió asilo a los babilonios, quienes se compadecieron de él y lo acogieron en su recinto. Zopiro, entonces, aprovechó la tranquilidad de la noche para abrir las puertas de la ciudad a su rey y conseguir la victoria.

Finalmente, el episodio se cierra con la descripción de las ruinas del zigurat de Borsipa, que Miró parece haber extraído de La Bible et les découvertes en Palestine, Egypte et Assyrie de Vigouroux ${ }^{71}$ :

La invadían cortezas de líquenes cenicientos, óxidos devoradores, albarazos eomo de una aridez lunar. Se le desgajaban peñas apócrifas de ladrillos crudos de color de limón podrido, de ladrillos cocidos de un color de rosa viseeral. Monte labrado todo por esfuerzo humano: ladrillo y pez; manos y fuego $\sin ^{72}$ una suavidad de naturaleza. Se le caían las arcadas de los revestimientos, te los frisos con las leyendas de Nabukodonosor, los colores de cada prisma, toda la una la gloria como la carne de un cadaver. Y en la última meseta, entre las quijadas rotas de las pretiles ${ }^{73}$ se movían las figuritas de los sacerdotes y rodeadas de aves que volaban con un silencio te alas de paño y a veces bajaban sus gritos te metálicos que removían los ladridos en talados todos los muladares (Cuart. 15r [2], "Bethlem. Magos [I]").

En cuanto a la tercera disposición, tomamos en cuenta el texto de la redacción III. A. 3, una de las versiones más avanzadas y completas que sigue, con algunas variaciones, el texto de la anterior. Como en esta última, la narración comienza con la contemplación de los cultivos y los canales de riego babilonios y con el encuentro con los buhoneros armenios.

${ }^{71}$ El fragmento que podría haber servido de inspiración a Miró aparece a continuación: "À douze kilomètres au sud-ouest de Hillah, l'ancienne ville proprement dite de Babylone. On rencontre là une énorme masse de ruines informes, composées de briques en partie vitrifiées par le feu, qui, en s'éboulant, ont produit de véritables collines: c'est Birs-Nimroud, «la tour de Nemrod», l'antique Borsippa... Le Birs, dans son état actuel, a encore quarante-six mètres de hauteur. Son pourtour, au niveau du sol, sans tenir compte des inégalités, est de sept cent dix mètres. La côté sud-ouest est escarpé. On y pénètre du côté de l'est par un ravin qui monte insensiblement. Cette partie du monument est en briques cuites. On croirait voir d'abord un monceau de terre informe... Un enorme pan de mur de l'antique tour de Nabuchodonosor est encore debout... Il est construit en briques d'un rouge pâle. Une couche de lichen le couvre presque entièrement et la végétation de ces cryptogrammes, sous un ciel aussi ardent, montre combien de siècles on déjà passé sur ces ruines. De nombreux oiseaux s'abritent en cet endroit. Tout autour du pan de mur, la place est jonchée de débris de briques de Nabuchodonosor, d'une teinte jaunâtre, et de blocs énormes de briques tombés d'en haut. Plusieurs de ces blocs portent des traces de vitrification produite par le feu" (t. 2, pp. 293-296).

72 Tachado: sin.

73 Tachado: almenas. 
Continúa con el fragmento, algo modificado, en el que el grupo de caminantes habla sobre la torre de Borsipa, cuyos contornos se empiezan a advertir en la lejanía. La sección se abre con la intervención del patriarca de la tribu, que hace una descripción del templo muy similar a la que en la segunda disposición aparecía en boca del camellero anciano. Seguidamente, el autor inserta la alusión a la cita de Abydena, que en la fase anterior se encontraba situada en un momento más avanzado de la conversación. Poco después, un camellero aporta los datos sobre la rampa, la estatua del dios y las cámaras de los sacerdotes, que en la segunda textualización daba un mayoral. A esta intervención sigue la del patriarca de la tribu, que recuerda las dos mismas citas del Génesis que aparecían anteriormente. Y a continuación, Miró introduce una variante: Melchor pregunta al patriarca la razón de que bendiga una obra de maldición, a lo cual responde el judío:

-Obra de maldición ${ }^{74}$. despues. Pero antes ${ }^{75}$ había juntado a los hombres ${ }^{76}$ Los hombres en una sola familia; como mis hijos y mis nietos y mis mujeres y mis rebaños y mis siervos son todos una misma ${ }^{77}$ casa abierta en lo ancho de nuestras jornadas. Yo algunas veces me paro a mirarlos. Todos criaturas mías y hacienda mía; con la misma palabra, la misma vereda o el mismo desierto, la misma felicidad o el mismo dolor. Por ellos perduraré. Así Dios se paró a mirar complacerse en los hombres imajen suya. Pero vió ${ }^{78}$ el mal en sus corazones. Y yo reverenció y beso la obra de la desgracia del hombre y de la primera congoja divina (Cuartilla 17r [1], "Bethlem. Magos [I]").

Comentario que contestan dos mujeres, las cuales, sonriendo, preguntan:

$-{ }_{¿} \mathbf{N o}^{79}$ levantó un rey encima de los escombros maldecidos de Bab-Bel la gran ziggurat de las Siete Esferas? ¿Por

${ }_{-¿}$ Pues por qué ${ }^{80}$ fue implacable el Señor con los hombres primeros y con su obra y ha consentido que ${ }^{81}$ otros la las acaben ${ }^{82}$ ? (Cuartilla $17 \mathrm{r}$ [1], "Bethlem. Magos [I]").

${ }^{74}$ Añadido signo de puntuación.

75 Tachado: Antes.

${ }^{76}$ Eliminado signo de puntuación: punto.

77 Tachado: $m i$.

${ }^{78}$ Tachado: Vió.

79 Tachado en la línea principal: Nabukodonossor, en la superior: Un rey.

80 Tachado: ¿̨Por qué.

81 Tachado: $a$.

${ }^{82}$ Aparecía escrito en primer lugar: la misma obra dejándola que el ti[empo]; después, ha tachado el ti[empo] y ha añadido: únicamente el tiempo la deshaga? Poste- 
Y a esto responde el anciano con otra pregunta: " $-;$ Đelfuego de un incendio puede salir ${ }^{83}$ el furego det saerifieio! ¿ No sale de la leña podrida la llama pura?".

Como en la disposición anterior, la narración de este pasaje termina constatando la incomprensión que provoca en los Magos la discusión anterior, que se vuelve a relacionar con la sombra del monumento maldito.

El fragmento que sucede a éste es, como en la segunda disposición, aquél en que se narra el paso de los Magos por la ciudad y se describen su arquitectura, su pueblo y sus costumbres. Aunque con pequeñas modificaciones, sigue el texto de la segunda textualización casi hasta el final, en donde Miró incluye la visita de los Magos al barrio judío. Esta parte, que ha elaborado seguramente teniendo en cuenta las entradas "Babylone" y "Babylonie" del Dictionnaire de la Bible de Vigouroux, comienza con una presentación de la zona y de sus pobladores:

Đe allí salieron a Callejones ${ }^{84}$ terronosos de bajas viviendas con hortali$\operatorname{llos}^{85}$ de legumbres, con talleres solar o taller. Eran los albergues de los judíos descendientes de los deportados por Salmansar o Nabukodonossor. Hortelanos, cardadores, alfareros, tejedores. Ellos mediaban entre drogueros y tintoreros de Sidon y los telares de Parthia. Llevaban paños tistosos de muchos colores, $\mathbf{y}$ gorros de piel dura que asemejaban mitras persas; $\mathbf{y}^{86}$ guardaban en sus arcas los lienzos y vestiduras de los israelitas puros para las peregrinaciones de las fiestas del Señor; y sobre las mudanzas de los tiempos y los trastornos del país que los hizo suyos acentuaban las prendas de su raza, acallaban sus escrúpulos recargándose las sienes ${ }^{87}$ y los brazos de de $^{88}$ pergaminos $\operatorname{con}^{89}$ los textos rituales (Cuartillas 19r [1] y 20r [1], "Bethlem. Magos (I)").

Y continúa con la transcripción del diálogo que entablan los judíos del barrio con los Magos. Los primeros cuentan a los sacerdotes zoroastristas que allí vivió Hyrcan, después de haber sido raptado

riormente, ha reemplazado todo el conjunto por acabasen la torre y, más tarde, ha sustituido torre por obra. A continuación, ha cambiado esta última opción por las acaben. Finalmente, ha sustituido las por la.

83 Tachado: beneficiarse.

${ }^{84}$ Modificado: callejones.

85 Tachado: hortales.

86 Tachado: pero.

87 Tachado: pulsos y las.

${ }^{88}$ Tachado en la línea principal: $d e$, en la superior: con los.

${ }^{89}$ Tachado: $d e$. 
y desorejado por Antígono ${ }^{90}$, y nacieron Ananel, sumo sacerdote, y Hillel $^{91}$, presidente del Sanhedrín. Y añaden sobre el último:

-Se lo llevaron te-chico a Jerusalem. En Jerusalem subía al terrado de la escuela porque era de familia pobre y no tenía el óbolo de la lección. Y una tarde que nevaba, se sintió su quejido, y lo recogieron morado y duro del helor, como un muerto. Desde la infancia se le señalaba y respetaba por su saber. Y hasta Herodes, tan temido de todos, le llama desde su trono, y le sonríe y le escucha en sus apuros. Pero Hillel ha de venir. Como yo, morirá en Babilonia. Nos envía su promesa con todas las caravanas. Pasa de ${ }^{92}$ mis años, y yo doblé los ochenta. Y tendión ${ }^{93}$ sus manos que le pesaban como losas hacia la ruta de la ła ciudad de David. Otra vez el cansancio de las palabras de los hombres $\tan ^{94}$ lejos, tan descuidados de las claridades inocentes de la estrella nueva (Cuartillas 20r [1] y 21r [1], "Bethlem. Magos [I]").

Finalmente, como la segunda disposición, la tercera se cierra con los apartados dedicados a narrar la historia de la rendición de Babilonia por parte de Darío, gracias a la ayuda de Zopiro, y la descripción de las ruinas del otrora majestuoso monumento de Borsipa.

\section{Conclusiones}

El análisis de las diferentes composiciones relativas al capítulo "III. Riegos. Borsipa. Babilonia” indica que Miró sometía a continua revisión su obra, lo que nos da una idea cabal del riguroso compromiso que mantenía con ella. Además, como se puede inferir a partir de la observación y la lectura detenida de los manuscritos, esta depuración no afecta solamente el plano formal del texto, sino sus aspectos narrativo e histórico.

Miró consultó diversas fuentes (bíblicas, históricas o literarias; clásicas o contemporáneas) durante el proceso de redacción de Figuras de Bethlem en un afán por dotar a su texto de plasticidad descriptiva, pero también de verosimilitud. Su relato, rico en erudición, no pierde, sin embargo, un ápice de su naturalidad, porque el autor selecciona muy bien la información que quiere transmitir para que

90 FLAVIO Josefo es quien transmite esta información sobre Hyrcan en su obra Antigüedades judías. Miró tenía dos ediciones de las Obras completas del escritor israelita que contenían este libro: una de 1838 y otra publicada entre 1900 y 1904, aunque las marcas en las páginas de la primera y el análisis del texto parecen sugerir que ésta fue su referencia principal.

91 Esta información es posible que la tomase Miró de STAPFER s.a., p. 286.

92 Tachado: Tiene.

93 Tachado: alzó.

94 Tachado: que no veían la estrella nueva esperándolo todo de la tierra caduca. 
no desentone con el sentido general, tanto textual como significativo, de la narración.

Miró es un novelista, no un investigador. Por eso, aunque fuentes contemporáneas como el Dictionnaire de la Bible de Vigouroux sean una referencia tan importante como Heródoto en la configuración de este apartado, decide hacer explícita su deuda con el escritor de la Antigüedad, pero no con el manual histórico, ya que le interesa eliminar, citando sus propias palabras, "el olor a lámpara" para transmitir una sensación de autenticidad, de verdad artística.

Asimismo, trabaja en la disposición del texto tanto como en la depuración lingüística para mantener el ritmo narrativo a la vez que la belleza, el simbolismo y la sugerencia, lo que dota al capítulo de gran calidad literaria.

Por lo demás, la fascinación que Miró sentía por la historia de Babilonia, la preocupación que demuestra por conocer los últimos descubrimientos arqueológicos, el interés por recrear de la forma más atenta posible su arte y su cultura traspasan el papel y acaban contagiando al lector, hechizado por su evocación.

Pero quizá la mayor importancia del capítulo resida en su contenido filosófico y humanístico, en esa esperanza en el progreso del ser humano que simbolizan los Magos, que acaba siendo sacudida por la duda existencial que recorre Figuras de Bethlem y que en este capítulo se manifiesta en el fragmento en el que se narra la llegada de los sabios al antiguo zigurat de Borsipa.

El desconcierto ante el mundo y lo humano recorren "Magos". Los sacerdotes son presentados como seres puros e ingenuos que han permanecido la mayor parte de su existencia encerrados en su santuario y, por lo tanto, aislados de la sociedad. Cuando advierten en el cielo la estrella, que ellos interpretan como el signo del nacimiento del salvador de la humanidad, abandonan su vida rutinaria y cómoda y emprenden un viaje para seguirla que les obliga a atravesar unos 2000 kilómetros de territorio en camello. Por su camino, tratan de propagar la buena noticia, pero aquellas personas que van encontrando a su paso les muestran su desprecio o, en el mejor de los casos, su indiferencia. El idealismo de los Magos choca estrepitosamente contra la prosaica realidad. El ejemplo más paradigmático de ello es la masacre de los inocentes que provoca su visita al rey Herodes, toda vez que el soberano, al interpretar literalmente los textos sagrados que profetizan el advenimiento de un nuevo rey, manda matar a todos los menores de dos años.

Esto desencadena una progresiva concienciación de los sacerdotes zoroastristas sobre la imposibilidad de alcanzar la utopía imaginada. El narrador parece sugerir la reflexión de que todas las ideas brillantes que se han esbozado para dirigir a la humanidad hacia el progreso terminan siendo irrealizables. Así, los Magos acaban 
preguntándose cuál es el sentido último de su viaje cuando están a punto de llegar a su destino:

\begin{abstract}
¿Nos habremos engañado nosotros? unieamente nosotros? ¿No será una estrella como todas las estrellas? Una estrella que ha salido ahora despues de surcar lo profundo del firmamento, y que volverá a penetrar en otras noches recónditas y volverá salir para otros ojos cuando los suyos esten ya derretidos en el polvo como se han deshecho ya los ojos de los profetas? que Pero por haberla prometido esos hombres tesaparecidos. Por ${ }^{95}$ eso el ${ }^{96}$ necesitarla ${ }^{97}$ el mundo las gentes afanadas ${ }^{98}$ no era el astro de la verdad feliz? (ff. 48r [1] y 49v [1], "Bethlem. Figuras de Bethlem. 10 cuartillas").
\end{abstract}

Ese cuestionamiento se hace especialmente evidente en este capítulo cuando, a la vista del monumento de Borsipa, después de que alguien haya recordado la cita del Génesis sobre la torre de Babel, que se identifica con el zigurat, y su reconstrucción, auspiciada por Nabucodonosor, una de las mujeres hermosas pregunta por qué los dioses fueron tan severos con los hombres antiguos al derribarlo, pero no con el rey cuando lo reedificó, lo que trata de justificar el viejo patriarca utilizando una metáfora, la de la madera podrida de la que sale la llama pura, que sume más en la perplejidad a los Magos, los cuales, a pesar de que escuchan con atención la disputa, se manifiestan incapaces de comprenderla.

Nos parece que la respuesta de los sacerdotes cabría interpretarla teniendo en cuenta la línea de relativismo existencial e ideológico que azota "Magos". Los sabios zoroastristas muestran su perplejidad ante el espectáculo de la heterogeneidad del alma humana, el comportamiento de las gentes o sus pasiones. Aunque salieron de Persia convencidos de su misión, de las bondades que su labor podía deparar a la humanidad, el cansancio, las penalidades, la incomprensión que han sufrido a lo largo de su trayecto empiezan a socavar su confianza, y la incertidumbre sobre el sentido de su viaje se adueña de su pensamiento.

Si tenemos en cuenta que Miró todavía se encontraba en pleno proceso de escritura de esta obra cuando le sobrevino la muerte de forma repentina en 1930, no nos sorprenderá que el clima de crisis política, económica, social y de valores que reinaba en ese momento histórico en España tiñera su obra de pesimismo y desconfianza.

Pero también es cierto que esta visión desencantada convive en Figuras de Bethlem con un sentimiento de solidaridad, con la defensa de la dignidad humana y la esperanza en el progreso que, en este

95 Tachado: no era $y$.

96 Modificado: la.

97 Tachado: mismo afán.

98 Tachado: de sus ojos sabedores del cielo. 
apartado concretamente, encarna en la figura de los tres Magos, quienes a pesar del cansancio, las dudas o las vacilaciones siguen caminando hacia su destino con la luz del ideal de salvación de la humanidad todavía brillando en sus ojos, lo que dota al texto de Miró de un sentido trascendente, de profundidad filosófica y ética, por la que, junto a su calidad literaria o su tremenda originalidad, nos parece que esta obra merece ser rescatada del olvido.

\section{REFERENCIAS}

\section{Manuscritos del legado personal del autor}

Miró, Gabriel. Legado Gabriel Miró, Biblioteca Gabriel Miró de Alicante, Carpeta "Bethlem. Figuras de Bethlem".

Miró, Gabriel. Legado Gabriel Miró, Biblioteca Gabriel Miró de Alicante, Carpeta "Bethlem. Figuras de Bethlem. 10 cuartillas".

Miró, Gabriel. Legado Gabriel Miró, Biblioteca Gabriel Miró de Alicante, Carpeta "Bethlem. Figuras de Bethlem. Figuras que hablan con los Magos".

Miró, Gabriel. Legado Gabriel Miró, Biblioteca Gabriel Miró de Alicante, Carpeta "Bethlem. Magos (I)".

\section{Referencias bibliográficas}

Biasi, Pierre-Marc de 2011. La génétique des textes, CNRS Éditions, Paris.

Castellón, José 1927. "Novelistas de España. Entrevista con Gabriel Miró”, Diario de Alicante, 26 de marzo.

Giménez Caballero, E. 1928. "Visitas literarias. Gabriel Miró”, El Sol, 20 de abril.

GrÉSILlon, Almuth 1984. Élements de critique genetique. Lire les manuscrits modernes, PUF, Paris.

JENOFONTE 1882. Historia de la entrada de Ciro el Menor en el Asia y de la retirada de los diez mil griegos que fueron con él. Trad. Diego Gracián, Luis Navarro, Madrid.

Jenofonte 1882. La Ciropedia o Historia de Ciro el Mayor. Trad. Diego Gracián, Luis Navarro, Madrid.

Josefo, Flavio 1838. Oeuvres complètes, Auguste Desrez, Paris.

Josefo, Flavio 1900-1904. Oeuvres complètes. Dir. Théodore Reinach. Ts. 1-3: Antiquités judaïques. Livres I-XV. Trad. Julien Weill, Ernest Leroux, Paris.

Hay, Louis 2002. La littérature des écrivains. Questions de critique génétique, Librairie José Corti, Paris.

Heródoto 1898. Los nueve libros de la Historia. Trad. Bartolomé Pou, Hernando, Madrid, 2 ts.

Miró, Gabriel 1916-1917. Figuras de la Pasión del Señor, E. Domenech, Barcelona, 2 ts.

Miró, Gabriel 1931. "Autobiografía”, La Gaceta Literaria, 1 de junio.

Miró, Gabriel 1932-1949. Obras completas. Edición conmemorativa, Altés, Barcelona.

Miró, Gabriel 1952. Glosas de Sigüenza. Introd. de Clemencia Miró, Espasa Calpe, Buenos Aires.

Miró, Gabriel 1961. Figuras de Bethlem. La conciencia mesiánica en Jesús, Losada, Buenos Aires.

Miró, Gabriel 2007. Obras completas. Ed. M.A. Lozano, Biblioteca Castro, Madrid, 3 ts. 
Miró, Gabriel 2009. Epistolario. Eds. Ian R. Macdonald y Frederic Barberà, Instituto Alicantino de Cultura "Juan Gil-Albert”-Caja Mediterráneo, Alicante.

Palomo Alepuz, Laura 2012. "Los nueve libros de la historia de Heródoto en Figuras de Bethlem de Gabriel Miró", Cuadernos de Aleph, 4, pp. 146-164.

Palomo Alepuz, Laura 2017. Posibles fuentes de "Figuras de Bethlem", Publicaciones de la Universidad de Alicante, Alicante.

Palomo Alepuz, Laura 2018. "Aspectos relacionados con la génesis de Figuras de Bethlem, obra de Gabriel Miró", Revista de Literatura, 80, 159, pp. 197-222, doi: https://doi.org/ 10.3989/ revliteratura.2018.01.008.

Pastor Platero, Emilio (comp.) 2008. Genética textual (J. Bellemin-Noël, P.M. de Biasi, R. Debray-Genette, A. Grésillon, L. Hay, J.L. Lebrave), Arco/Libros, Madrid.

Stapfer, Edmond s.a. La Palestine au temps de Jésus-Christ, Fischbacher, Paris.

Vigouroux, Fulcran 1879-1882. La Bible et les découvertes modernes en Palestine, en Égypte et en Assyrie, Berche et Tralin, Paris, 4 ts.

Vigouroux, Fulcran (éd.) 1912-1922. Dictionnaire de la Bible, Letouzy et Ané, Paris, 10 ts.

\section{ANEXO \\ CRITERIOS PARA LA TRANSCRIPCIÓN DEL TEXTO}

IDENTIFICACIÓN DE LOS DOCUMENTOS:

1. Folio, cuartilla u octavilla: para una hoja que va numerada, seguida de su número $\mathrm{X}$ de folio (si no estuviera numerada también se haría constar); de la aclaración $r$ (para recto) o $v$ (para verso); de un número entre paréntesis que indica el orden de aparición (para el caso de varios folios con la misma numeración) en esa carpeta y que puede ir seguido de letra (A, B, C, y así sucesivamente) para marcar diferentes versiones de un mismo folio. Además, el número para el verso siempre será el mismo que lleve el recto, independientemente del lugar que ocupe. Ejemplo: f. 7r (2) (A) indica que, además de tratarse de un folio 7 , recto, es el segundo con tal número de foliación encontrado en esta carpeta y que es la primera versión de este folio (pero también que hay otras posteriores).

2. Nota: para hojas no numeradas que contengan anotaciones.

3. Мapa.

4. Sobre.

5. Índice.

DENTRO DE Un DOCUMENTO:

6. En cuanto a las faltas de ortografía, o las incoherencias sintácticas o semánticas, respetaremos el texto original, aunque no siga las reglas actuales o sea incorrecto desde un punto de vista lingüístico.

7. Tachado: con este recurso señalaremos que ha habido una rectificación en el manuscrito.

8. Negrita: una o varias palabras aparecerán en negrita cuando reemplacen a otra que se halla tachada; suelen aparecer sobre la línea tachada. Dejaremos en el cuerpo del texto, en negrita, las que no han sido eliminadas; las que se han rechazado aparecerán en nota al pie precedidas de la indicación pertinente, en cursiva. Se destacarán en negrita las palabras tachadas en la línea superior o inferior a la principal en el cuerpo del texto.

9. Modificado: si una palabra ha sido parcialmente reescrita, se indicará en nota a pie de página. 
10. Añadido: si el autor ha añadido, en una revisión posterior, alguna palabra o signo de puntuación.

11. Cuando nos encontremos con dos tachaduras o más, unas encima de las otras, dejaremos la que está sin tachar en el cuerpo del texto, y la trascripción de las palabras tachadas se hará en nota al pie. Con ello intentamos respetar el orden en que han tenido lugar los cambios.

12. (*): señala una llamada a nota que indicó el propio Miró mediante diferentes símbolos. Utilizaremos solamente éste para no desconcertar al lector.

13. //: encontramos frecuentemente en los borradores que una anotación comienza en determinada cuartilla, pero continúa en otro lugar, ya sea en el dorso de ésta o en otra, extensión que, la mayoría de las veces, se anuncia con una flecha u otro símbolo. En este caso, reproduciremos el texto unido, porque creemos que de esta forma se facilitará su lectura y comprensión. Además, utilizaremos la barra doble para señalar el fragmento que aparecía desplazado. 